\title{
Avaliação formativa no ensino superior: avanços e contradições
}

\author{
Natália Luiza Silva \\ Olenir Maria Mendes
}

Resumo: Neste trabalho, destacaremos alguns dados obtidos a partir de pesquisa sobre a avaliação das aprendizagens em cursos de graduação da Universidade Federal de Uberlândia (UFU) que têm a avaliação formativa como diretriz em seus projetos político-pedagógicos. O objetivo da investigação foi analisar os processos de avaliação das aprendizagens nesses cursos e verificar em que medida constituem uma avaliação para as aprendizagens, cumprindo seu papel pedagógico. $\mathrm{O}$ estudo foi desenvolvido em três etapas. A primeira consistiu na análise documental dos projetos político-pedagógicos dos cursos em questão. Posteriormente, foram analisados os planos de ensino dos componentes curriculares ministrados nesses cursos. Na última fase da pesquisa, foram feitas entrevistas com professores(as) que demonstraram em seu plano de ensino mais indícios de realizarem a avaliação formativa. Traremos, neste artigo, alguns elementos identificados na pesquisa, buscando provocar reflexões sobre as práticas avaliativas na Universidade. Antes disso, faremos algumas considerações sobre a lógica que fundamenta a avaliação educacional, bem como sobre o entendimento de avaliação formativa que embasa nossas análises. De modo geral, foi possível verificar, com a investigação, que houve um avanço, embora pequeno, no discurso da Instituição, por meio de seus documentos oficiais de planejamento. Alguns deles já explicitam a necessidade de a prática avaliativa ocorrer numa perspectiva formativa. Por outro lado, tanto nos planos de ensino quanto nas entrevistas foram identificados elementos incoerentes com os princípios da avaliação formativa.

Palavras-chave: Avaliação das aprendizagens. Avaliação formativa. Ensino superior.

\section{Formative assessment in higher education: progresses and contradictions}

Abstract: In this paper, we point out some data obtained from research on learning assessment in undergraduate courses of the Federal University of Uberlândia (Universidade Federal de Uberlândia-UFU) which have formative assessment as a guideline in their political-pedagogical projects. The objective of investigation was to analyze the assessment processes of learning in these courses and to check to what extent they are also part of learning, fulfilling their pedagogical role. The study was conducted in three stages. The first stage constituted the documentary analysis of political-pedagogical projects of the courses in question. Secondly, the teaching plans of syllabus components taught in these courses were analyzed. The last stage of the research consisted of interviews with professors who showed in their teaching plans more indications of putting formative assessment in practice. In this paper, we present some elements identified in the research, trying to cause reflection on assessment practices at the University. Before that, we make some considerations about the logic basing the educational assessment as well as about the understanding of formative assessment basing our analysis. On the whole, it was possible to check with this research that there was a progress, though small, on the Institution's discourse, through its official planning documents. Some of them have already made explicit the need that the assessment practice occurs in a formative perspective. On the other hand, incoherent elements with the principles of formative assessment were identified both the teaching planes and the interviews.

Key words: Learning assessment. Formative assessment. Higher education. 


\section{Introdução}

Vivemos atualmente no Brasil um momento de reformas da educação superior. Iniciativas como a Lei de Cotas constituem uma tentativa de democratizar o ingresso nesse nível de ensino e diminuir, gradativamente, a exclusão social das camadas menos favorecidas que tem se consolidado historicamente em nosso país. Para que isso ocorra, está havendo uma mudança do perfil dos(as) estudantes que ingressam nas Instituições Federais de Educação Superior. Essas instituições estão passando a receber cada vez mais estudantes oriundos(as) de escolas públicas e pertencentes às classes populares. Com todos os problemas já conhecidos do ensino público no Brasil, isso significa receber um contingente significativo de discentes com muitas lacunas formativas. As práticas didático-pedagógicas desenvolvidas para as aprendizagens desses(as) estudantes, sobretudo no que se refere ao processo de avaliação das aprendizagens, serão um dos fatores determinantes para que o objetivo de democratização seja alcançado.

Por um lado, os processos formativos de avaliação para as aprendizagens, considerando o ponto de partida do(a) educando (por mais aquém que esteja do desejável), podem contribuir para que ele(a) se desenvolva nos aspectos cognitivo, profissional, pessoal, ético e crítico. Por outro lado, a avaliação das aprendizagens numa abordagem classificatória, com influência positivista, pode, somada a outros fatores, contribuir para o aumento do número de reprovações e, consequentemente, para o represamento e até mesmo a evasão de estudantes, substituindo a exclusão por falta de acesso pela exclusão por carência de condições de conclusão do ensino superior.

Partimos da premissa de que o eventual fracasso no campo da avaliação das aprendizagens, conforme destaca Sordi (2005), não pode ser, levianamente, imputado ao(à) professor(a), que tem sofrido muita pressão para solucionar problemas que não foram criados por ele(a), mas que é fruto de uma sociedade desigual em que à educação tem sido atribuída a função de atender aos interesses do sistema produtivo. Para que haja mudanças nas práticas didático-pedagógicas, será também necessária uma revisão das funções atribuídas à educação, pois há muitos obstáculos (e mesmo impedimentos), em decorrência do projeto capitalista que tem definido nossas instituições de ensino. Por isso, a autora defende um desvelamento competente da realidade: ao assumir que nem tudo é possível, considerando-se as condições limitantes do contexto histórico-social, são criadas condições políticas de se fazer o historicamente possível. 
Nesse contexto se insere a Universidade Federal de Uberlândia - UFU, que possui 77 cursos de graduação, ${ }^{1}$ sendo seis na modalidade a distância, 11 sediados no Campus Pontal, na cidade de Ituiutaba, três no Campus Monte Carmelo, três no Campus Patos de Minas e 54 distribuídos entre os três campi da cidade de Uberlândia. Esses últimos compuseram o universo de um estudo realizado como parte do curso de Mestrado em Educação na própria Instituição. Dentre eles, identificamos 24 que estabelecem em seus Projetos Político-pedagógicos de Curso - PPCs a avaliação formativa como diretriz para as práticas avaliativas.

A partir disso, buscamos investigar: Como é desenvolvida a avaliação das aprendizagens nesses cursos que têm como diretriz a avaliação formativa? Em que medida ela constitui também avaliação para as aprendizagens, cumprindo seu papel pedagógico? Mais especificamente, o que buscamos compreender é: O que se entende, no âmbito desses cursos, por avaliação formativa? Qual a relação entre o que é proposto nos PPCs e o que os(as) professores(as) desses cursos comunicam quanto às suas próprias práticas avaliativas? Dentre esses cursos, há alguma distinção da cultura avaliativa predominante nas licenciaturas e nos bacharelados?

Para melhor compreensão, esclarecemos, com base nas ideias de Fernandes (2009), a distinção entre avaliação das aprendizagens e avaliação para as aprendizagens. A primeira ocorre com o diagnóstico acerca das aprendizagens conquistadas, isto é, identifica-se o que foi aprendido (e o que ainda não foi) dentre os conhecimentos, habilidades e atitudes estabelecidos como meta a ser alcançada. Quando esse diagnóstico é utilizado em favor das aprendizagens dos(as) estudantes, transforma-se também em avaliação para as aprendizagens. Nesse caso, o(a) docente retomará, com cada grupo de estudantes, os conteúdos ainda não aprendidos, propondo novas atividades e realizando novas discussões até que o objetivo do trabalho educativo seja atingido. Assim, a avaliação passa a cumprir um papel pedagógico fundamental: direcionar os próximos passos a serem dados e guiar o trabalho do(a) professor(a) e do(a) discente.

A pesquisa foi realizada em três etapas. Primeiramente, foi feita uma análise documental dos 24 projetos político-pedagógicos que apresentam a avaliação formativa como diretriz. O intuito foi identificar, de forma mais detalhada, as bases teóricas e as concepções de avaliação das aprendizagens assumidas nas propostas. Posteriormente, dentre os 24 projetos, selecionamos uma amostra constituída de seis cursos, sendo dois de cada

1 Levantamento realizado em 2013. 
grande área (ciências exatas, humanas e biomédicas), um bacharelado e uma licenciatura (articulada ou não com o bacharelado), para as etapas seguintes. Na segunda fase foi realizada análise documental dos planos de ensino dos(as) professores(as) que ministraram aulas nesses cursos no primeiro semestre letivo de 2014. Na análise dos planos observamos as propostas de avaliação das aprendizagens feitas pelos(as) professores(as) do curso, comparando-as com a teoria da avaliação formativa. Além disso, tivemos o intuito de identificar os(as) professores(as) que apresentavam maiores indícios de realizarem a avaliação de seus(as) estudantes em uma abordagem formativa, para seleção dos que participariam da próxima fase da investigação, constituída de entrevistas reflexivas. Nessas entrevistas, buscamos compreender melhor o entendimento desses(as) professores(as) acerca da avaliação das aprendizagens de modo geral e de avaliação formativa, em especial.

Neste trabalho, destacaremos alguns dados obtidos a partir da pesquisa. Sendo assim, não temos aqui a intenção de apresentar um panorama geral dos resultados do estudo. Mas traremos alguns elementos, buscando provocar reflexões, a nosso ver, muito importantes. Antes disso, faremos apenas algumas considerações sobre a lógica que fundamenta a avaliação educacional, bem como sobre o entendimento de avaliação formativa que embasa nossas análises.

\section{A lógica que tem norteado as práticas avaliativas}

A temática das práticas avaliativas tem ganhado cada vez mais relevância nas discussões promovidas no âmbito da Associação Nacional dos Dirigentes das Instituições Federais de Ensino Superior (ANDIFES) e, consequentemente, no campo das universidades federais. Isso ocorre em razão do impacto que os índices de evasão e represamento nos cursos de graduação irão causar na definição do montante de recursos financeiros a ser recebido por instituição, segundo a nova matriz de distribuição orçamentária estabelecida pelo Decreto n. 7.233, de 19 de julho de 2010, e orientada pela Portaria n. 651, de 24 de julho de 2013 do MEC. Se antes era considerado apenas o número de vagas ofertadas, agora os parâmetros para o cálculo dos recursos incluirão a quantidade de estudantes matriculados(as) e de concluintes. Sendo assim, quanto menor o número de concluintes em relação ao de ingressantes, menor será a verba destinada à instituição. Trata-se de uma questão bastante delicada, que não pode ser ignorada pelas universidades. 
Por outro lado, é preciso que essa discussão seja conduzida com cautela, ética e tendo como princípio norteador a função social da educação superior.

Esse tipo de política está embasado no princípio da eficiência dos gastos públicos e é fruto da influência neoliberal. Ao mesmo tempo, porém, pode suscitar no interior das IFES o interesse pela discussão acerca das práticas avaliativas dos seus(as) professores(as). E consideramos a criação de espaços institucionais para essa discussão imprescindível, para que a diminuição dos índices de reprovação e represamento nos cursos de graduação não ocorra negligenciando as aprendizagens dos(as) estudantes, como vimos acontecer em diversos sistemas de educação básica.

Como já mencionamos, a garantia da qualidade do ensino ofertado é condição para que nos aproximemos do cumprimento do objetivo de democratização da educação superior. Defendemos que as práticas avaliativas tanto podem ser utilizadas a favor da efetiva democratização quanto para uma exclusão mascarada - daí a importância de se discutir a teoria e a prática da avaliação das aprendizagens nesse contexto.

A esse respeito, Luckesi (2008), ao falar da relação entre a democratização do ensino e a avaliação do(a) estudante, reforça que tal democratização implica não só o ingresso no processo de escolarização, mas a permanência do(a) educando(a) na escola, com consequente terminalidade escolar, e a garantia da qualidade do ensino, que provoca a apropriação ativa do conhecimento e sua capacidade de relacioná-lo à realidade. É também nesse sentido que Fernandes (2009) apresenta a necessidade de se refletir sobre a adequação da educação que se tem oferecido a todos os(as) jovens e adultos(as). Para tanto, propõe alguns questionamentos:

Será que todos os alunos têm as mesmas oportunidades para aprender? Será que todos recebem feedback adequado relativamente a seus progressos e dificuldades?

Será que todos podem ir tão longe quanto suas motivações, interesses e saberes lhes permitirem?

Será que todos, em suas diferenças, sejam quais forem, se sentem plenamente integrados e vêem satisfeitas suas legítimas aspirações? Será que a todos é proporcionada uma educação e uma formação que lhes permitam integrar-se plena e dignamente na sociedade? (FERNANDES, 2009, p. 39-40).

Conforme Freitas (2005), o modelo de escola predominante em nossa sociedade é baseado em determinada visão de mundo e de educação construída historicamente. Sendo assim, por se constituir no interior de uma 
sociedade de desigualdades, dentro da escola também se formam campos de poder constituídos de maneira assimétrica. Nesse contexto, ao se discutir os caminhos para promover mudanças no âmbito das instituições educativas, um debate recorrente é o dos efeitos dos fatores pedagógicos internos à escola em contraposição aos aspectos externos, já que eles disputam importância. É necessário considerar, porém, de acordo com o autor, que o conjunto desses fatores tem relação intrínseca na construção da realidade educacional.

Com a ascensão da política econômica neoliberal, a educação também sofreu um processo de desregulação e/ou desconstrução, que significou a transferência do controle do público/coletivo para as regras do mercado e do indivíduo, abrindo caminho para um "eu" individualista. Trata-se de um processo descrito por Freitas (2005) como a proletarização cultural que acompanhou a proletarização econômica. Nesse contexto, é preciso destacar que:

[...] as finalidades correntes da escola atual não se destinam à inclusão e ensino para todos. Ao contrário, nossa escola foi configurada, ao longo da história moderna, para dar um mínimo de conhecimentos e habilidades a todos, mas separar os mais competentes e ensinar de fato a estes (FREITAS, 2005, p. 122).

Nesse sentido, a escola recebeu, ao longo de sua história, duas funções principais que foram atribuídas às instituições e aos(às) professores(as): "“...] a exclusão do sistema de ensino dos alunos das classes sociais inferiores e a que definimos como socialização à subordinação, isto é, a transmissão ao jovem de valores compatíveis com o seu futuro papel de subordinado" (TRAGTENBERG, 1982 apud FREITAS, 2005, p. 131).

O processo de avaliação e o consequente uso da nota foram alguns dos mecanismos criados para o cumprimento das duas funções supracitadas. Segundo Freitas (2005), a finalidade do processo de avaliação nunca foi apenas de verificar as aprendizagens, mas também de estabelecer um controle sobre o comportamento dos(as) estudantes, seus valores e atitudes. Assim, o poder do(a) professor(a) se constituiu a partir do controle da avaliação do(a) discente. $\mathrm{O}$ autor explica, ainda, que:

Este processo de controle pela avaliação firmou-se em dois planos: um formal e outro informal. [...] No plano da avaliação formal estão as técnicas e procedimentos palpáveis de avaliação com provas e trabalhos que conduzem a uma nota; no plano da avaliação informal estão os juízos de valor invisíveis e que acabam por influenciar os 
resultados das avaliações formais finais, sendo construídos pelos professores e alunos nas interações diárias. Tais interações criam, permanentemente, representações de uns sobre os outros (FREITAS, 2005, p. 132).

Conforme Freitas (2005), a parte mais dramática e relevante da avaliação ocorre no plano informal, em que o jogo de representações, tanto do(a) professor(a) para com o(a) estudante, quanto do(a) estudante para com o(a) professor(a), constrói imagens e autoimagens que "[...] terminam interagindo com as decisões metodológicas que o professor implementa em sala de aula" (FREITAS, 2005, p. 132).

Em síntese, pode-se dizer que:

[...] os procedimentos de avaliação estão articulados com a forma que a escola assume enquanto instituição social, o que, em nossa sociedade, corresponde a determinadas funções: hierarquizar, controlar e formar os valores impostos pela sociedade (submissão, competição, entre outros). Isso é feito a partir de uma triangulação entre avaliação instrucional, comportamental e de valores e atitudes, cobrindo tanto o plano formal como o plano informal (FREITAS, 2005, p. 133).

Por outro lado, segundo o autor, constituiu-se a luta por uma escola democrática, que atenda a todos(as) com qualidade, sob pressão de forças progressistas. Para ele, sem que haja resistência às finalidades originais da escola, de controle, hierarquização e seleção de indivíduos, elas acabam se cumprindo. Não é do interesse do poder dominante propiciar o acesso à cultura para as massas; portanto, somente por meio de lutas, ou quando o próprio processo de acumulação de riquezas passou a necessitar de avanços nesta direção, foi facultado às classes menos privilegiadas o acesso às escolas. A partir daí, instala-se uma contradição entre a manutenção e a eliminação dessas classes dentro da escola capitalista. ${ }^{2}$

Em outras palavras, Freitas (2005) explica que a pressão por acesso à escola aumentou, tanto a política quanto a social, por manter as crianças

2 Capitalismo, segundo Sousa Junior (2000), é o modo de produção que se consolidou a partir do desenvolvimento do capital. Ele explica que o capital "[...] é um sistema social produtor de mercadorias, que tem como sentido último a produção de valor excedente. Caracteriza-se ainda pela relação salarial em que a força de trabalho é trocada como mercadoria, sua relação fundamental." (p. 45). Nesse sentido, o capital se assenta na divisão social do trabalho, que separa proprietários dos meios de produção, aos quais cabem os lucros, e trabalhadores, aos quais cabem os salários, numa relação que é reproduzida constantemente. A escola capitalista seria, então, aquela que, inserida na sociedade em que predomina o modo de produção capitalista, atende de modo acrítico às suas demandas e serve de instrumento de reprodução e manutenção das relações sociais já estabelecidas. 
na escola (longe dos perigos da rua). Por isso, foram necessárias mudanças na organização escolar para liberar o fluxo de estudantes, racionalizar custos e, assim, evitar pressões econômicas adicionais. Com isso, também se modificaram os processos de exclusão.

Freitas (1991) apresenta uma dialética entre a manutenção e a eliminação dos(as) estudantes da escola capitalista que contém quatro soluções para essa contradição, sendo uma delas a "eliminação adiada", ou seja, a manutenção provisória das classes populares no interior da escola ou o prolongamento de sua presença nesse local, mas sem aprendizagem real; trata-se, pois, de uma nova forma de exclusão, que atua por dentro do sistema. Conforme o autor, não se exclui o(a) estudante fisicamente, mas, por meio da avaliação informal, são criadas outras formas de exclusão:

As novas formas de exclusão ancoram seu poder na avaliação informal. A saída da nota como elemento de reprovação formal abriu espaço para que a avaliação informal tomasse o lugar da avaliação formal na sala de aula. Entretanto, os processos de avaliação informal negativos atingem diretamente a auto-estima do aluno e podem ser mais perversos do que a própria avaliação formal. Do ponto de vista do sistema, entretanto, a exclusão foi internalizada a custos menores - tanto econômicos como políticos (FREITAS, 2005, p. 135).

Em síntese, a exclusão passou a ocorrer de novos modos, passando a atuar por dentro da escola. A eliminação dos(as) estudantes é adiada, e estes(as) internalizam o processo de exclusão, o que permite maior tempo para a formação de atitudes de subordinação e obediência, típicas das estruturas historicamente construídas na escola. Por meio da avaliação informal são construídas trilhas diferenciadas de progressão, com diferenciados momentos de terminalidade ou com a exclusão sendo feita em anos posteriores da estrutura escolar, quando a evasão já é tida como algo "mais natural e aceitável".

Essa descrição é muito pertinente para pensarmos o atual contexto da educação superior no Brasil. Por mais que tenhamos visto algumas iniciativas com o intuito de democratizar o acesso a esse nível de ensino, o fato de não se garantir a conclusão com qualidade aos(às) estudantes das camadas menos favorecidas faz com que a democratização não chegue a se efetivar. Trata-se, assim, de uma exclusão por dentro do sistema, de uma eliminação adiada, ou "branda", nas palavras de Bourdieu e Champagne (2001, p. 223): 
[...] eis aí um dos mecanismos que, acrescentando-se à lógica da transmissão do capital cultural, fazem com que as mais altas instituições escolares e, em particular, aquelas que conduzem às posições de poder econômico e político, continuem sendo exclusivas como foram no passado. E fazem com que o sistema de ensino, amplamente aberto a todos e, no entanto, estritamente reservado a alguns, consiga a façanha de reunir as aparências da democratização.

Em contrapartida, destacamos que, conforme Freitas (2005), ainda é preferível um(a) estudante que permaneça do lado de dentro do sistema, mesmo que sem aprender, e possa denunciar esta escola que lhe nega até mesmo a alardeada cidadania liberal, do que tê-lo(a) excluído(a) dessa Instituição de ensino e silenciado(a).

Diante dessa realidade, é relevante, conforme alerta Silva (2009), compreender que a avaliação escolar é uma prática social que, por si só, não é capaz de gerar exclusão. Trata-se de uma categoria do aparente que está a serviço de uma lógica muito mais ampla. Ela deve ser analisada como pertencente a uma rede mais abrangente de categorias, a do capital. Sendo assim, é preciso desnudar os âmbitos mais amplos das relações, sobretudo em termos econômico-produtivos e político-sociais, examinando as relações de determinações da realidade social.

Nesse sentido, a autora explica que: "Não é necessariamente a avaliação que é excludente, pois sabemos que a própria exclusão faz parte da lógica do sistema do capital" (SILVA, 2009, p. 9125). Por isso, acreditamos que a mudança das práticas avaliativas não será o bastante para estabelecer novos paradigmas educacionais (ou mesmo sociais), se a lógica interna da realidade social for a mesma. É preciso fazer resistência à lógica do sistema do capital como um todo, pois é seu enfraquecimento poderá enfraquecer também suas consequências em termos de práticas sociais. E, de fato, tal resistência só será possível a partir da conscientização das pessoas, também por meio do trabalho educativo.

\section{A avaliação formativa: um novo paradigma}

Em contraposição à avaliação classificatória e excludente está a proposta da avaliação formativa. Isso significa que ela só faz sentido dentro de um movimento mais amplo de resistência à lógica do modelo liberal conservador de sociedade. Sabemos que a forma como o(a) professor(a) vê o mundo e sua concepção de sociedade está diretamente ligada ao seu ideal de ser 
humano. Essas concepções fundamentam suas ideias sobre a educação que, por sua vez, têm relação estreita com o modo como compreende a avaliação. Se ele(a) não reflete sobre essas concepções para (re)construí-las de modo consciente, o que acontece é que acaba por reproduzir, por força da cultura instituída, o modelo social vigente, contribuindo, junto de outros mecanismos, para sua manutenção.

A avaliação formativa só é coerente com a luta por uma sociedade democrática, justa, participativa e com igualdade de oportunidades, em que todos(as) possam ter garantidas dignas condições materiais de vida e de acesso ao conhecimento socialmente construído. Só será coerente se considerarmos que o ser humano está em processo constante de constituição e desenvolvimento. Segundo essa visão, mesmo que em ritmos diferentes, todos(as) são capazes de aprender, desde que assegurados os meios e os recursos necessários. E essa seria, então, um dos principais desafios da educação. Nesse contexto, a avaliação ganha outra dimensão dentro do trabalho educativo. Assim, passamos a discorrer sobre a avaliação a partir dessa abordagem.

Segundo Villas Boas (2009), expressões como avaliação mediadora, emancipatória, dialógica, fundamentada ou cidadã têm sido utilizadas para se falar de avaliação formativa no Brasil. Autores(as) como Luckesi (2008), Vasconcellos (2007), Saul (2008) e Hoffman (1994) têm trabalhado nessa perspectiva utilizando diferentes terminologias. Independentemente da nomenclatura usada, os posicionamentos desses(as) autores(as) pertencem a um mesmo paradigma de avaliação, que passamos a caracterizar a seguir.

Vasconcellos (2007) explica que a avaliação é um processo abrangente da existência humana, que implica reflexão crítica sobre a prática para captar seus avanços, resistências e dificuldades, além de possibilitar uma tomada de decisão sobre o que fazer para superar os desafios existentes. Tratando da avaliação escolar mais especificamente, o autor ratifica que é, antes de tudo, uma questão política, pois está relacionada aos objetivos e às finalidades do trabalho educativo, que não são neutros. Sua defesa é pela pedagogia que tem como meta a construção da autonomia e da solidariedade; nesse contexto, a avaliação passa a ser uma referência para o(a) próprio(a) estudante, para superar as dificuldades que venha a ter.

Vasconcellos (2007) alerta, porém, que essa concepção de avaliação, denominada por ele como dialético-libertadora, exige uma mudança de postura por parte do(a) professor(a). Este precisará investir suas energias 
e potencialidades não no controle acerca daquilo que foi "transmitido", e sim nas aprendizagens dos(as) estudantes.

De modo semelhante, Saul (2008) também reforça que a avaliação não é uma ação neutra, já que implica uma opção de valor. Para a autora, diferentes práticas e definições de avaliação decorrem de variados entendimentos acerca da educação. Sendo assim, a avaliação é coerente em relação à prática educativa como um todo: sua defesa é por uma avaliação chamada por ela de emancipatória, que prevê práticas democráticas, afinadas a uma concepção de educação libertadora, conforme proposto por Freire (1997). Essa avaliação teria dois objetivos básicos: indicar o caminho da transformação e beneficiar os(as) envolvidos, tornando-os(as) autodeterminados(as). Além disso, inclui elementos como a emancipação, a decisão democrática, a transformação e a crítica educativa. Nesse sentido, a conscientização é vista como fundamental.

Saul (2008) apresenta algumas características da avaliação emancipatória que nos ajudam a compreendê-la: tem função diagnóstica e auxilia o autoconhecimento do(a) educando(a); contribui para que ele(a) participe ativamente do seu processo de construção das aprendizagens; tem compromisso com uma educação democrática; propõe uma relação democrática entre professor(a) e educando(a); ajuda o(a) discente a aprender e o(a) docente a ensinar; auxilia o(a) professor(a) a reorganizar suas ações; prioriza aspectos qualitativos do desenvolvimento do(a) estudante; enfatiza o processo e o resultado das aprendizagens; e é participativa.

Outra perspectiva que, a nosso ver, se inclui dentro do paradigma da avaliação formativa é a de Hoffmann (1994). A autora fala da avaliação mediadora, que constitui uma ação reflexiva e desafiadora do(a) educador(a) para contribuir com a troca de ideias entre (e com) seus(as) estudantes. Nesse sentido, favorece a produção de um saber enriquecido, elaborado a partir da compreensão dos fenômenos estudados. Para a autora:

A avaliação, enquanto relação dialógica, vai conceber o conhecimento como apropriação do saber pelo aluno e também pelo professor, como ação-reflexão-ação que se passa na sala de aula em direção a um saber aprimorado, enriquecido, carregado de significados, de compreensão. Dessa forma, a avaliação passa a exigir do professor uma relação epistemológica com o aluno uma conexão entendida como reflexão aprofundada a respeito das formas como se dá a compreensão do educando sobre o objeto do conhecimento (p. 56). 
Mas Luckesi (2008) aponta que frequentemente as instituições de ensino têm se limitado à verificação das aprendizagens e não chegam a realizar a avaliação efetivamente. Segundo o autor, nossa prática educativa tem se caracterizado por três procedimentos básicos: medida do aproveitamento escolar; transformação da medida em nota ou conceito; utilização dos resultados identificados, na quase totalidade das vezes, para classificar os(as) estudantes em aprovados(as) ou reprovados(as).

De acordo com ele, o processo de verificação se dá pela observação, obtenção, análise e síntese dos dados que delimitam o objeto ou ato com o qual se está trabalhando; chega-se, pois, à conclusão de que tal objeto ou ato possui determinada configuração. Por outro lado, o ato de avaliar implica coleta, análise e síntese dos dados que configuram o objeto da avaliação, acrescido de uma atribuição de valor ou qualidade, que se processa ao comparar a configuração do objeto avaliado com um determinado padrão de qualidade previamente estabelecido para aquele tipo de objeto. O valor ou qualidade atribuído ao objeto conduz a uma tomada de posição, e esse posicionamento conduz a uma decisão nova: manter o objeto como está ou atuar sobre ele.

Sendo assim, conforme Luckesi (2008), a avaliação, diferentemente da verificação, envolve um ato que ultrapassa a obtenção da configuração do objeto, exigindo uma decisão do que fazer ante (ou com) ele. A verificação é uma ação que congela o objeto; a avaliação, por sua vez, direciona o objeto numa trilha dinâmica de ação. Em síntese, o atual processo de aferir as aprendizagens escolares, sob a forma de verificação, além de não obter as mais significativas consequências para a melhoria do ensino e das aprendizagens, impõe aos(às) educandos(as) consequências negativas, como a de viver sob a égide do medo, pela ameaça de reprovação.

Para o autor, a prática da avaliação para as aprendizagens, em seu sentido pleno, só será possível na medida em que se está efetivamente interessado nas aprendizagens do(a) educando(a), ou seja, é preciso estar interessado em relação ao que o(a) estudante aprende (e que está sendo ensinado), e não apenas em sua aprovação. Se, ao ensinar, os(as) discentes não aprenderam, mas há interesse que aprendam, deve-se ensinar até que aprendam, investindo na construção dos resultados desejados. A avaliação só pode funcionar efetivamente num trabalho educativo com essas características.

Villas Boas (2009) acrescenta que, para Black e Wiliam (1998, p. 7 apud VILLAS BOAS, 2009), assim como para Sadler (1989, p. 120 apud VILLAS BOAS, 2009), o elemento-chave da avaliação formativa é o feedback. Esse 
termo é entendido como a informação acerca da distância entre o nível de desenvolvimento alcançado pelo(a) estudante e aquele fixado como objetivo, desde que essa informação seja utilizada para diminuir tal distância. Dessa maneira, será aliada tanto do(a) professor(a) quanto do(a) discente: ao(à) primeiro(a), fornecerá um diagnóstico que permitirá a reorganização do seu trabalho; e ao (à) segundo(a), possibilitará a identificação de potencialidades e fragilidades em seu desempenho, indicando-lhe o caminho para melhorar suas aprendizagens. Nesse processo, o(a) educando(a) deverá conhecer os objetivos do trabalho educativo, sendo capaz de comparar o seu nível atual de desempenho com o que foi estabelecido como objetivo e se empenhando na realização de ações adequadas para a aproximação contínua entre esses dois pontos.

Diferencia-se do feedback o que a autora chama de automonitoramento. Enquanto o primeiro fornece informações coletadas por fonte externa ao(à) estudante, o segundo é realizado mediante informações percebidas pelo(a) próprio(a) discentes - em ambos os casos, tais informações serão qualitativas e detalhadas. É importante destacar que a avaliação formativa inclui os dois elementos (feedback e automonitoramento) e se aproxima da autorregulação, conforme a proposta de Fernandes (2009). A ideia é possibilitar, gradativamente e de modo contínuo, a transição do feedback para o automonitoramento, consolidando a autonomia intelectual do(a) estudante. Isso significa que o desenvolvimento da capacidade de automonitoramento compõe o conjunto de aprendizagens a serem adquiridas.

Feitas essas considerações, passamos a apresentar alguns elementos identificados em nossa pesquisa sobre as práticas avaliativas no âmbito dos cursos de graduação da UFU que têm como diretriz a avaliação formativa em seus Projetos Pedagógicos. Sobre eles, também propomos algumas reflexões.

\section{Sobre as concepções de educação dos(as) professores(as)}

As entrevistas realizadas com professores(as) da Universidade dão indícios do modo como compreendem a educação. Destacamos esses indícios porque acreditamos que tais entendimentos constituem a base de suas concepções de avaliação; ou seja, possuem uma estreita relação entre si.

$\mathrm{Na}$ fala de um dos(as) professores(as) entrevistados(as) é possível perceber a crença demonstrada em certo determinismo quanto ao desempenho dos(as) estudantes, em função de suas "vocações" e "aptidões". O professor afirma: 
A minha forma de trabalho é com aquelas pessoas que têm interesse. Eu também não faço, como às vezes os pedagogos falam, o desafio pedagógico, que é pegar uma pessoa que não tem a mínima vocação ou que tem muita dificuldade e vou trabalhar com ela para que consiga. Do ponto de vista de uma Universidade Federal, que é mantida por fundos públicos, eu não sei se isso é um bom uso dos recursos públicos. Para quê vou gastar tantos recursos com uma pessoa que não tem muita vocação, sendo que eu posso gastar esse mesmo recurso no desenvolvimento de cinco ou dez pessoas que já têm uma vocação para isso? [...] Às vezes se a pessoa não tem uma boa performance, muito provavelmente ela não tem interesse ou ela está no lugar errado. [...] Do ponto de vista da pedagogia, o problema é ser criticado em relação a isso, é achar que você deveria trabalhar todas as pessoas. Eu não enxergo as coisas dessa forma (Professor do curso 24-H/B).

É possível observar que questões econômicas relacionadas à racionalidade dos gastos públicos são consideradas mais importantes que o desenvolvimento humano das pessoas e seu direito social à educação. Trata-se de um posicionamento com o qual não concordamos e que não é coerente com a proposta de educação em que cabe a discussão sobre a avaliação formativa, conforme a qual é preciso empregar os meios e os recursos necessários (não só financeiros, mas, sobretudo, didático-pedagógicos) para garantia da qualidade plena das aprendizagens. Entretanto, a fala destacada ilustra como, para muitos(as) professores(as), a lógica do capital é preponderante. De modo semelhante, outro professor expressa:

Então tem três tipos de estudantes, o bom estudante, o sem base nenhuma, que caiu de paraquedas ali no curso, e o mediano. Os medianos são aqueles com os quais temos que ter maior cuidado, pois os outros dois, independentemente do tipo de avaliação que você der, um vai sair muito mal e o outro muito bem. [...] Tem a faixa dos alunos que vão mal e que acabam largando o curso em algum momento. Raramente um desses alunos, por algum motivo que eu desconheça, seja por pressão da familia ou porque está passando por um periodo na faculdade em que esteja aproveitando, começa a estudar muito, e esse aluno passa para o time mediano. [...] O bom ou o ruim vai responder do mesmo jeito sempre. Os ruins incluem aluno com pouca aptidão para exatas ou que não estuda nada (Professor do curso 8-E/B).

Primeiramente ressaltamos, a partir dessa fala, a cautela necessária na condução da avaliação informal, que distingue estudantes "bons", "ruins" e "medianos". Freitas e outros (2013) aborda essa questão dizendo que o juízo de valor que o(a) professor(a) constrói do(a) estudante no plano da avaliação informal influencia a tal ponto suas práticas e a interação com esse(a) discente se refere a uma relação entre docente e educando(a) que aprova ou reprova. Isso porque, a partir de alguns elementos objetivos, o(a) 
professor(a) cria um processo interno de análise que normalmente impacta na forma como trata o(a) estudante e culmina na atribuição da nota ou do conceito. Ainda segundo o autor, é importante esclarecer que o problema não é a existência de um juízo de valor, mas o modo como ele afeta a relação entre professor(a) e estudante. Coloca-se o desafio em que o(a) docente aprende a lidar com o juízo de valor construído na perspectiva de mudar a situação do(a) estudante, ao invés de fazê-lo na perspectiva do determinismo.

Sendo assim, a ideia determinista, no que diz respeito ao desempenho dos(as) estudantes, parece supor a inalterabilidade de sua situação acadêmica. Para Fernandes (2009), a avaliação formativa está alicerçada em uma cultura avaliativa que considera como objetivo da avaliação a melhoria das aprendizagens, auxiliando os(as) estudantes a superarem suas dificuldades a partir da compreensão de que todos(as) podem aprender. Se partirmos do pressuposto de que a capacidade para as aprendizagens está condicionada à "aptidão" para construir determinado conhecimento ou à "vocação", o debate acerca da avaliação formativa perde o seu sentido. Por isso, antes mesmo de se discutir sobre a avaliação formativa, será preciso refletir sobre a concepção de educação na qual ela se baseia, que só pode ser uma educação para promover uma sociedade mais democrática, em que todos(as) têm direito e aptidão para o conhecimento.

\section{Os procedimentos avaliativos}

Em nossa pesquisa, ao analisarmos os planos de ensino dos(as) professores(as), um dos itens observados foram os procedimentos de avaliação. Passamos, a seguir, a fazer alguns destaques, dentre os dados analisados, que demonstram como, apesar de no discurso contido no texto dos PPCs os cursos se aproximarem, muitas vezes, da concepção de avaliação formativa, as práticas pedagógicas dos(as) professores(as), em geral, ainda está muito distante de refletir esse entendimento acerca da avaliação.

O primeiro elemento que nos chamou atenção foi a predominância da utilização da prova, aliada ou não a outros procedimentos avaliativos, em todos os cursos participantes dessa etapa da investigação. Além disso, ao falarmos sobre a distribuição das notas, pudemos observar também que a maioria das propostas avaliativas que incluem a prova e outros procedimentos enfatiza a prova, atribuindo-lhe a maior parcela da nota.

É interessante destacar que, muitas vezes, é construído um clima de tensão em torno da aplicação da prova, o que pode desestabilizar emocionalmente 
o(a) estudante e impactar de modo negativo nos seus resultados. Verificamos, por exemplo, em planos de ensino de dois cursos da Instituição, a informação de que poderá ser solicitada a apresentação do documento de identidade do(a) discente por ocasião das provas e exames. Não sabemos se as turmas dos componentes curriculares em questão são tão volumosas a ponto de o(a) professor(a) não conseguir reconhecer os(as) seus(as) alunos(as). De todo modo, acreditamos que esse tipo de prática pode prejudicar o ambiente para a realização da prova, que deve ser também um momento de aprendizagens, e não de tensão e de desconfiança.

Outro ponto pertinente é relativo a uma afirmação que encontramos em planos de três cursos, de que é proibido o uso de calculadoras e celulares durante as provas. Moretto (2010) comenta essa questão dizendo que o uso da calculadora é até recomendável. Afinal, se as instituições de ensino preparam o(a) estudante para a cidadania e o exercício profissional, no caso da universidade, é preciso considerar que, para um grande número de profissionais, o acesso à informação por meio de tablets, celulares, calculadoras etc. não é apenas um recurso disponível, mas condição indispensável à realização do seu trabalho. Por isso, saber consultar o que for necessário para a resolução de situações complexas é uma das competências que precisa desenvolver. De fato, é importante que as atividades propostas tenham significado e não constituam apenas operações realizadas a partir da memorização e de abstrações.

Nas entrevistas realizadas com professores(as) também surgiram falas como: "E uma coisa que nós já sabemos é que prova é a pior maneira de avaliar, só que nós não conseguimos fugir dela porque é a mais conveniente para o professor. Nessa correria toda, você acaba mesclando prova com outras atividades avaliativas" (Professor do curso 1-B/B). Ou ainda:

Eu gostaria de fazer o trabalho prático mesmo. Mas em função desse comportamento, que nós chamamos de vadiagem social [...], que é o fato de você ter um grupo e nem todo mundo participar da mesma forma, isso não é possível. Tem alguns que são os "caronistas". Colocam apenas o nome. Por isso, eu preciso ter algum instrumento de avaliação individual para identificar isso também. Mas se não houvesse esse desvio, eu escolheria trabalhar mais do ponto de vista prático do que ter prova. Muita gente fala que prova não avalia o aluno. Então me apresente algum outro instrumento que avalie que eu uso (Professor do curso 24-H/B).

Acreditamos que o(a) professor(a) deve fazer suas escolhas no que diz respeito ao processo avaliativo, sobretudo por questões pedagógicas que 
estejam relacionadas ao interesse em promover as aprendizagens dos(as) estudantes, e não por outros motivos. Defendemos que, ao utilizar a prova, o(a) professor(a) o faça consciente de suas limitações, alie-a a outros procedimentos avaliativos (distribuindo melhor o peso dado a cada procedimento avaliativo) e a elabore com todo o rigor necessário. Além disso, a prova deve ser uma opção pedagógica, e não o resultado do desconhecimento de outras possibilidades, da busca de praticidade ou da desconfiança em relação ao trabalho dos(as) estudantes.

Outro ponto que julgamos relevante retomar ao falar da utilização da prova é o cuidado que se há de ter para não se reproduzir o que Luckesi (2008) chama de "pedagogia do exame", em que toda a prática educativa passa a estar polarizada por provas e exames. Essa preocupação surge a partir de falas como:

Às vezes a gente tem de se adequar ao aluno. O aluno não é aquele que estuda todos os dias. O aluno estuda no aperto. Ele vai estudar dois dias antes da prova. [...] Mais perto da prova, ele está estudando, já está no aperto, ai ele aprende mais. E depois da prova também (Professora do curso 16-H/L).

Outro professor também manifesta: "Os estudantes detestam prova. Eles têm uma carga horária muito grande e acabam deixando para estudar na última hora, na véspera da prova" (Professor do curso 1-B/B). Parece que está claro para os(as) professores(as) que os(as) estudantes ficam condicionados a estudar apenas em função da prova. Nesse sentido, os acontecimentos relativos aos processos de ensino e das aprendizagens ficam em segundo plano, ganhando prioridade a prova e seus resultados em termos de nota. Conforme Luckesi (2008), as consequências dessa pedagogia do exame são: pedagogicamente, ela centraliza a atenção nas provas e não auxilia as aprendizagens dos(as) estudantes; psicologicamente, é útil para desenvolver personalidades submissas; sociologicamente, a avaliação das aprendizagens utilizada de forma fetichizada é bastante útil para os processos de seletividade e exclusão social.

Além disso, essa ênfase dada à prova suscita uma preocupação quanto à possibilidade de distorções no processo avaliativo provocadas pela sua qualidade como instrumento de coleta de dados. Luckesi (2014) explica que um instrumento de coleta de dados, acerca do desempenho do(a) educando(a) em suas aprendizagens, precisa ser elaborado com o mínimo de rigor metodológico. Isso significa dizer que deve possuir características como sis- 
tematicidade, linguagem compreensível, precisão e compatibilidade entre o ensinado e o aprendido; caso contrário, não será capaz de demonstrar as aprendizagens dos(as) estudantes. Sendo assim, ter consciência das possíveis fragilidades no processo de elaboração da prova implica conscientizar-se de que as notas escolares, ao se assentarem sobre os dados coletados por meio dela, são enganosas, dado que sua base "material" pode não possuir a consistência necessária.

Não estamos defendendo aqui a abolição do uso de provas, já que nenhum procedimento é formativo ou não em si (tudo depende do uso que se faz dele). Apenas estamos chamando a atenção para suas limitações, sobretudo quando, mesmo em meio a outros procedimentos avaliativos, recebe tanta ênfase. Além disso, propomos uma reflexão sobre suas características. Ora, uma prova em que o(a) estudante precisa demonstrar a memorização de conceitos apenas estaria adequada no âmbito de um trabalho educativo voltado para a memorização de conteúdos. Se, ao invés disso, o objetivo é formar para a cidadania crítica, o exercício profissional consciente e a capacidade de reflexão, buscando instrumentalizar os(as) estudantes a partir da construção de conhecimentos que, no contexto da vida real, podem ser utilizados para a transformação social, esse a prova voltada para a devolução de conteúdos memorizados parece incoerente.

Ressaltamos também que alguns planos de ensino apresentaram, como um dos procedimentos avaliativos, o teste de memória. Em um deles, a professora explica que "[...] serão realizados imediatamente ao final de algumas aulas e abordarão uma questão sobre o tema exposto no dia". A nosso ver, esse tipo de proposta também está relacionado a uma concepção de aprendizagem que a entende como mera memorização de conteúdo. A avaliação formativa, conforme defendemos, só será possível a partir de outro entendimento acerca das aprendizagens, baseado em princípios decorrentes do construtivismo, da psicologia social, das teorias socioculturais e sociocognitivistas. Aliás, segundo Fernandes (2009), uma das razões para que haja mudança nas práticas avaliativas, em busca de uma perspectiva formativa, é justamente o desenvolvimento das teorias de aprendizagens. Para ele, antes de tudo é preciso compreender que a organização e o desenvolvimento da avaliação se relacionam às concepções de aprendizagens.

Também identificamos dois planos de ensino, ambos do mesmo professor, que apresentam como procedimento a autoavaliação e a tradução de textos relacionados ao conteúdo do componente curricular da língua inglesa para a língua portuguesa. No tocante à autoavaliação, em um dos casos o professor 
chegou a lhe atribuir 30\% da nota do semestre. Villas Boas (2009) explica que a autoavaliação não deve visar que o(a) próprio(a) estudante atribua sua nota. Ao invés disso, tem como intuito promover a reflexão do(a) discente acerca de suas aprendizagens, desenvolvendo nele(a) a capacidade de registrar suas percepções sobre suas próprias aprendizagens e auxiliando-o(a) a identificar o próximo passo. Não temos subsídio suficiente para dizer se essa reflexão foi estimulada ou não, mas, de todo modo, achamos importante destacar tal aspecto.

O outro procedimento avaliativo proposto pelo professor - a tradução de textos do inglês para a língua portuguesa - não nos teria chamado a atenção, não fosse a natureza do curso e dos componentes curriculares. Um deles possui a seguinte ementa: "Síntese e Propriedades de Polímeros"; e seu objetivo é: "[...] ao final da disciplina o(a) estudante será capaz de conhecer os conceitos fundamentais envolvidos na química de polímeros". Já a ementa do outro componente é: "O núcleo atômico; Desintegração radioativa; Radioatividade natural e as leis da transformação radioativa; Reações nucleares; Reatores Nucleares; Radioproteção; Aplicações da Ciência Nuclear na Química, Biologia, Agricultura, Medicina, Indústria, etc."; e seu objetivo: "Proporcionar ao aluno conhecimentos básicos dos fenômenos que envolvem o núcleo atômico bem como das aplicações das radiações e radioisótopos nos diferentes ramos da Ciência".

No caso do primeiro componente curricular descrito, à tradução de textos relacionados ao conteúdo da disciplina se chegou a atribuir $70 \%$ da sua nota. Para nós, esse procedimento de avaliação é inadequado para acompanhar o desenvolvimento dos conhecimentos propostos, e acreditamos que a simples tradução de textos não conseguirá abarcar toda a complexidade da disciplina. Além disso, é preciso ressaltar que, ao se utilizar a tradução de textos em inglês como procedimento avaliativo, parte-se do pressuposto que o(a) estudante tem proficiência suficiente no idioma inglês, o que não é necessariamente verdadeiro. Apesar de ser desejável que o(a) discente de nível superior tenha domínio de pelo menos uma língua estrangeira, isso nem sempre acontece, e, quando domina outro idioma, nem sempre é o inglês. Lembramos, inclusive, que nos processos seletivos promovidos pela Instituição para o ingresso nos cursos de graduação, o(a) candidato(a) escolhe uma língua estrangeira que comporá o conteúdo da sua prova, sendo que ele(a) possui três opções: inglês, francês ou espanhol. E, se o ingresso ocorre pelo Exame Nacional do Ensino Médio (ENEM), ele(a) também pode optar por outra língua estrangeira que não o inglês. 
Dessa maneira, entendemos que, além de não estar adequado ao objetivo do componente curricular, o procedimento de avaliação proposto ainda promove a exclusão dos(as) educandos(as) que não têm domínio suficiente no idioma supracitado.

\section{As distorções no uso da nota}

Identificamos em sete planos de ensino analisados, ambos da área de ciências exatas, a informação de que será utilizada média aritmética para o cálculo da nota. Sobre essa questão, Luckesi (2008) explica que, para se empregar corretamente a avaliação no processo de ensino e de aprendizagens no contexto escolar, importa estabelecer um padrão mínimo de conhecimentos, habilidades e hábitos que o(a) educando(a) deverá adquirir, e não uma média mínima de notas, como ocorre muitas vezes - aliás, para ele o ideal seria, de fato, a inexistência do sistema de notas. A aprovação ou reprovação do educando dar-se-ia pelas efetivas aprendizagens dos conhecimentos mínimos, com o consequente desenvolvimento de habilidades, hábitos e convicções. Para isso, o(a) professor(a) teria de planejar o que é o mínimo necessário e trabalhar com os(as) estudantes para que todos(as) atingissem esse mínimo. Então, a avaliação seria um mecanismo subsidiário pelo qual o(a) docente detectaria os níveis de aprendizagens atingidos pelos(as) educandos(as) e trabalharia para que atinjam a qualidade ideal mínima necessária - só se passaria para um conteúdo novo quando os(as) estudantes tivessem atingido esse patamar mínimo.

Porém, ao invés disso, o que temos visto é a avaliação expressa em dados quantitativos, por meio da nota, para descrever um processo que é essencialmente qualitativo (as aprendizagens), como se os conhecimentos, as competências, as habilidades e as atitudes pudessem ser rigorosamente medidos a partir de um instrumento neutro. Nesse sentido, apesar de supostamente expressar a qualidade das aprendizagens, a nota acaba sendo utilizada e operada como se constituísse uma quantidade:

Como um fantasma, a nota opera por si, independente da qualidade que representa, ou seja, as notas escolares permitem proceder a operações aritméticas como se fossem quantidades numéricas. Hipostasiadas, [...] elas permitem "fazer processar matematicamente médias simples", como também "médias ponderadas", sem nenhuma referência à realidade à qual deveriam estar vinculadas (LUCKESI, 2014, p. 89). 
Encontramos também, por exemplo, nos planos de ensino de dois cursos, a informação de que a nota da prova substitutiva substitui a nota anterior, mesmo que isso resulte em uma nota final ainda menor. Ora, partindo do pressuposto de que é o mesmo conteúdo que está sendo avaliado e considerando que a nota deve expressar o desempenho do(a) estudante em relação aos objetivos traçados, não se pode dizer que, decorrido algum tempo, ele regrediu no alcance desses objetivos. Sendo assim, sua nota em avaliação posterior foi menor porque os critérios de avaliação não estão claros o suficiente ou porque o nível de domínio dos conhecimentos exigidos foi alterado.

Há, ainda, outros casos em que se explicita que a nota pode ser utilizada para punir o(a) estudante por algum motivo, a exemplo do atraso na entrega de trabalho (identificamos afirmações desse tipo em planos três dos seis cursos que participaram dessa etapa do estudo). Um dos planos especificou que: "Os trabalhos valerão 5\% a menos por dia de atraso". Em outro caso, o plano dizia: "Cada semana de atraso será descontado $10 \%$ da nota". Houve, ainda, uma situação em que o plano especificava: "Se houver atraso de 1 dia na entrega haverá desconto de $20 \%$ na nota deste item. Se o atraso for de 2 dias haverá desconto de $40 \%$ na nota deste item. Se o atraso for maior de 2 dias, o relatório não será mais aceito". Compreendemos que duas atitudes a serem desenvolvidas pelo(a) estudante são a responsabilidade e o compromisso no cumprimento dos prazos. Mas é preciso questionar até que ponto é válido utilizar a nota como um modo de punir o(a) discente não cumpre o prazo. Não seria isso distorcer a função da nota?

Observamos também que, em dois cursos, alguns planos propunham que “[...] caso o aluno obtenha média após realização de prova substitutiva será aprovado com 60 pontos" ou que "[...] a nota final dos alunos que fizerem a prova substitutiva será no máximo a menor nota obtida pelos alunos aprovados sem a prova substitutiva". Tais ocorrências demonstram que às vezes a nota final do(a) estudante e o alcance da média necessária ganham mais importância que as próprias aprendizagens. Além disso, tais propostas expressam desrespeito ao fato de que cada um tem um ritmo diferente para aprender. Ao que parece, o(a) discente que não aprende logo na primeira oportunidade não pode ser considerado tão bom quanto os(as) outros(as), mesmo que ele(a) prove que aprendeu.

Ainda sobre a questão da nota, identificamos, em três cursos, planos que informavam que a divulgação das notas das avaliações seria feita por 
meio de quadros de avisos ou murais nos corredores do prédio onde funciona o curso. Além da impessoalidade que marca esse tipo de prática, ela contraria um dos princípios fundamentais da avaliação formativa, que é a realização do feedback ao(à) estudante em relação ao seu desempenho. Se o(a) professor(a), mesmo quando trabalha em um curso presencial, sequer comunica pessoalmente o(a) discente acerca dos resultados da avaliação das suas aprendizagens, já que os disponibiliza em um mural, é muito provável que não converse com ele(a) sobre o significado desses resultados e nem $\mathrm{o}$ (a) oriente a partir deles. Aliás, um docente chegou a registrar em seu plano que as resoluções das listas de exercícios solicitadas por ele não seriam devolvidas aos(às) educandos(as), o que fere as Normas de Graduação da Universidade no art. 173, in verbis: "Vencidos os prazos estipulados para pedidos de revisão, o docente deverá devolver aos discentes todas as provas e outros tipos de avaliações do componente curricular".

Achamos relevante, ainda, destacar alguns aspectos das falas dos(as) professores(as) durante as entrevistas realizadas, também relacionadas à questão da nota. Qual seria a sua função? Por que utilizá-la, afinal? Qual a sua importância?

Na conversa com um dos(as) professores(as), ele admitiu utilizá-la apenas por obrigação. Segundo ele, trata-se de um número atribuído a cada estudante para informar à Universidade se ele(a) pode progredir no curso ou não, considerando que muitas vezes a aprovação em uma disciplina é pré-requisito para que se possa cursar outras. Ele explica que, se pudesse escolher, não utilizaria a nota, já que ela não é fundamental no trabalho educativo, mas sim o modo como esse trabalho é desenvolvido no cotidiano da sala de aula e as aprendizagens dos(as) estudantes. É nesse sentido que manifesta:

Então, de um modo geral, se o processo ou o momento com o aluno foi positivo, se eu sinto que a turma estava bem, respondeu bem, o semblante, um comentário... Se de um modo geral os textos revelam que houve um interesse legitimo em escrever aquilo, se a entrega da atividade foi com alegria, a questão do valor atribuído tem menor peso. Isso é o que estou tentando dizer. Não é que não tenha peso. Mas tem menor peso (Professor do curso 4-B/BL).

Por outro lado, outros dois professores acreditam que a nota seja importante para estabelecer um ranqueamento entre os(as) estudantes, conforme a dedicação e o mérito de cada um. Esclarecemos que o ranqueamento é uma preocupação muito mais coerente com uma visão de avaliação classificatória. Assim, um desses professores explica: 
A nota é para ser justo com aquelas pessoas que têm um desempenho superior. Aquilo que chamo de meritocracia, ou seja, aqueles que têm mais esforço geram mais resultados e deveriam ser melhor recompensados. Isso é algo com que eu me preocupo muito quando estou avaliando, principalmente os trabalhos dos alunos (Professor do curso 24-H/B).

Segundo Gentili (1996), uma das estratégias utilizadas em favor da hegemonia do neoliberalismo foi a construção de um novo senso comum, a criação de um projeto de reforma de valores sociais com base, sobretudo, na meritocracia. De acordo com o autor, as responsabilidades são atribuídas, individualmente, a cada pessoa, de modo que seu êxito ou fracasso são vistos, independentemente de suas condições sociais, como fruto do seu esforço e mérito. Nessa perspectiva, a avaliação é empregada segundo uma lógica classificatória e excludente, em que a cada um é dada a nota segundo seu mérito, como uma "recompensa" ou como reconhecimento do seu fracasso. Por isso, a nota é usada para se "fazer justiça", ao invés de indicar, mesmo que na maioria das vezes a partir de símbolos numéricos, a qualidade das aprendizagens. Desse modo, dar a nota torna-se mais importante que verificar a situação do(a) estudante em relação aos objetivos definidos e, a partir dessa informação, reorientar o trabalho pedagógico com o intuito de promover as aprendizagens necessárias. Trata-se de uma alienação à nota.

Vasconcellos (2007) aprofunda um pouco mais essa questão. Segundo ele, o fato de a nota ter se tornado mais importante que as aprendizagens é apenas um problema aparente que, apesar de real e perceptível, esconde outro problema, esse sim essencial: a avaliação como instrumento de discriminação e seleção social. Para o autor, o(a) professor(a) muitas vezes participa da distorção do sentido da avaliação dando destaque a ela, utilizando-a como instrumento de coerção, de controle e, em um nível mais profundo, a empregando (ou a reprovação) como elemento de discriminação social, com vistas a selecionar os(as) estudantes "que têm capacidade".

Num resgate histórico, ele explica que a reprovação na escola com o caráter que tem hoje se origina com a constituição da burguesia enquanto classe. A partir da formação dos estados nacionais modernos, os sistemas nacionais de ensino passam a ser organizados e, em decorrência do surgimento do capitalismo, a escola muda sua função, passando a visar a formação de mão-de-obra para a indústria. Nesse contexto, mais do que capacitar as classes populares, a escola passa a ter como finalidade o disciplinamento, preparando as pessoas para a ordem, o ritmo, o controle, a hierarquia, o trabalho para o outro, enfim, para se adequar ao sistema produtivo capitalista. 
O mito da ascensão social e a ideologia da doutrina liberal, de igualdade de oportunidades, serviram para justificar a submissão à escola. Entretanto, como o princípio básico do capitalismo é a concentração, nem todos podem ascender socialmente. Por isso, passa a ocorrer a reprovação, em tese como uma decorrência natural das diferenças entre os indivíduos, já que alguns conseguiram essa ascensão e outros, não.

Além disso, na fala desse mesmo professor, pudemos identificar a influência exercida pela avaliação informal na atribuição das notas:

Então, se eu percebo que a turma é responsável, eu procuro ser menos rigoroso com o piso das notas. Talvez eu desse 60 pontos para esse piso. Depois procuro distribuir as notas entre 60 e 100 pontos em função da qualidade. [...] Por outro lado, se eu noto que a turma não tem um bom comportamento e o pessoal não está nem aí, a nota vai lá embaixo mesmo. Nesse caso eu dou 20 pontos, 30 pontos... (Professor do curso 24-H/B).

A partir desse relato, é possível perceber que o comportamento dos(as) estudantes é o que define, de fato, a nota a ser atribuída. Tal comportamento é aferido por meio da avaliação informal que ocorre, invariavelmente, sem que haja um registro dessa aferição e sem que os(as) educandos(as) tenham consciência disso ou possam discuti-la com o(a) professor(a). Essa prática, em geral, cria uma distorção do uso da nota, posto que, como nos referimos, ela passa a ser empregada como prêmio ou punição (mais frequentemente como punição), ao invés de ser um registro que indica a qualidade das aprendizagens, tendo como parâmetro o objetivo traçado.

\section{Considerações finais}

Em síntese, a referida pesquisa permitiu identificar que, de modo geral, as práticas avaliativas desenvolvidas no âmbito dos cursos de graduação, mesmo daqueles que se propõem a realizar uma avaliação formativa, de acordo com seus PPCs, ainda estão muito longe de contribuir para efetivação da democratização do ensino superior. Por outro lado, foi possível perceber também que há professores interessados em refletir sobre suas próprias práticas, a fim de melhorá-las.

Compreendemos que é nessa contradição, é na identificação de aproximações e distanciamentos da avaliação formativa, que se torna possível construir um espaço fecundo de debate a respeito das práticas avaliativas. Todo processo de mudanças é lento e exige esforços; por conseguinte, é 
necessário um trabalho permanente para que, de maneira gradual, as transformações possam ocorrer. É na reflexão acerca dos avanços e estagnações, que estão em relação dialética, que se poderá construir novas realidades e buscar transformações. Para tanto, o planejamento coletivo, participativo e constante das ações é imprescindível.

E ainda, para que a discussão a respeito da avaliação das aprendizagens, assim como de qualquer outro elemento do trabalho pedagógico, possa ganhar espaço e relevância no meio acadêmico, é fundamental que a atividade de ensino seja mais valorizada no âmbito das universidades. Se não há valorização do ensino, também não haverá interesse em se discutir a qualidade do ensino ofertado ou os elementos que culminarão nessa qualidade.

Acreditamos, inclusive com base nos relatos dos(as) professores(as) durante as entrevistas, que as instituições de ensino superior precisam constituir em seu seio o espaço de formação permanente e desenvolvimento profissional de seus(suas) docentes. Sem esse espaço e sem a proposição de ações formativas que possam alcançar todo o seu quadro docente por meio de discussões e problematizações ancoradas nos dilemas vividos no cotidiano das salas de aula, não serão possíveis avanços em direção à melhoria da qualidade do ensino ofertado ou das práticas de avaliação das aprendizagens. É fundamental que o(a) professor(a) tenha a oportunidade de desvelar as concepções que embasam suas práticas, o que às vezes desenvolve de modo irrefletido, apenas repetindo as experiências que teve como discente, sem ter consciência de todos os desdobramentos dessa prática, como mecanismo de reprodução do modelo social vigente.

Assim, esperamos que este trabalho, apesar de suas limitações, possa contribuir com o debate e a compreensão mais aprofundada sobre a avaliação formativa das (e para as) aprendizagens. Isso, a nosso ver, é tão importante nesse momento histórico em que se discute a democratização do ensino superior não só na instituição pesquisada, mas também em outras instituições de ensino superior.

\section{Referências}

BOURDIEU, Pierre; CHAMPAGNE, Patrick. Os excluídos do interior. In: NOGUEIRA, Maria Alice; CATANI, Afrânio (Orgs.). Escritos de educação: Pierre Bourdieu. 3. ed. Petrópolis: Vozes, 2001. p. 217-227. 
FERNANDES, Domingos. Avaliar para aprender: fundamentos, práticas e políticas. São Paulo: Ed. UNESP, 2009.

FREIRE, Paulo. Pedagogia da autonomia: saberes necessários à prática educativa. 23. ed. São Paulo: Paz e Terra, 1997.

FREITAS, Luiz Carlos de. A dialética da eliminação no processo seletivo. Educação \& Sociedade, Campinas, n. 39, p. 265-285, 1991.

FREITAS, Luiz Carlos de. Eliminação adiada: novas formas de exclusão introduzida pelas reformas. Pro-posições, Campinas, v. 16, n. 3, p. 111-144, set./dez. 2005.

FREITAS, Luiz Carlos de et al. Avaliação educacional: caminhando pela contramão. 5. ed. Petrópolis: Vozes, 2013.

GENTILI, Pablo. Neoliberalismo e educação: manual do usuário. In. SILVA, Tomaz Tadeu da; GENTILI, Pablo. Escola S. A. - quem ganha e quem perde no mercado educacional do liberalismo. Brasília: CNTE/Confederação dos Trabalhadores em Educação, 1996. p. 9-49.

HOFFMAN, Jussara Maria Lerch. Avaliação mediadora: uma relação dialógica na construção do conhecimento. In: ALVES, Maria Leila et al. (Orgs.). Avaliação do rendimento escolar. São Paulo: FDE, 1994. p.51-59.

LUCKESI, Cipriano Carlos. Avaliação das aprendizagens escolar. 19. ed. São Paulo: Cortez, 2008.

LUCKESI, Cipriano Carlos. Sobre notas escolares: distorções e possibilidades. São Paulo: Cortez, 2014.

MORETTO, Vasco Pedro. Prova: um momento privilegiado de estudo, não um acerto de contas. 9. ed. Rio de Janeiro: Lamparina, 2010.

SAUL, Ana Maria. Referenciais freireanos para a prática da avaliação.

Revista de Educação PUC-Campinas, Campinas, n. 25, p. 17-24, nov. 2008 .

SILVA, Neyre Correia da. Exclusão e avaliação escolar. In: CONGRESSO

NACIONAL DE EDUCAÇÃO - EDUCERE, 9.; ENCONTRO SUL BRASILEIRO DE PSICOPEDAGOGIA, 3., 2009, Curitiba. Anais... Curitiba: PUCPR, 2009. 
SORDI, Mara Regina Lemes de. Avaliação universitária: mecanismo de controle, de competição e exclusão ou caminho para construção da autonomia, da cooperação e da inclusão? In: VEIGA, Ilma Passos Alencastro; NAVES, Marisa Lomônaco de Paula (Orgs.). Currículo e avaliação na educação superior. Araraquara: JM, 2005. p. 121-148.

SOUSA JUNIOR, Justino de. Capital. In: DUARTE, Adriana Maria Cancella et al. Dicionário da educação profissional. Belo Horizonte: Fidalgo \& Machado, 2000. p. 45-46.

VASCONCELLOS, Celso dos Santos. Avaliação: concepção dialéticalibertadora do processo de avaliação escolar. 17. ed. São Paulo: Libertad, 2007.

VILLAS BOAS, Benigna Maria De Freitas. Virando a escola do avesso por meio da avaliação. 2. ed. Campinas: Papirus, 2009.

Natália Luiza da Silva - Universidade Federal de Uberlândia Uberlândia | MG | Brasil. Contato: olenirmendes@gmail.com

Olenir Maria Mendes - Universidade Federal de Uberlândia Uberlândia | MG | Brasil. Contato: nat_luiza@yahoo.com.br

Artigo recebido em 23 de novembro de 2015 e aprovado em 18 de abril de 2016. 